\title{
Delay to initiate treatment is associated with unsuccessful treatment outcome among new pulmonary tuberculosis patients in Tigray, Northern Ethiopia: a follow up study
}

kiros Tedla ( $\sim$ kirosmerry12@gmail.com)

Mekelle University College of Health Sciences https://orcid.org/0000-0003-1566-7038

Girmay Medhin

Addis Ababa University

Gebretsadik Berhe

Mekelle University College of Health Sciences

Afework Mulugeta

Mekelle University College of Health Sciences

Nega Berhe

Addis Ababa University

\section{Research Article}

Keywords: pulmonary tuberculosis, treatment initiation, treatment outcome, community engagement

Posted Date: May 19th, 2021

DOI: https://doi.org/10.21203/rs.3.rs-527930/v1

License: (c) (1) This work is licensed under a Creative Commons Attribution 4.0 International License.

Read Full License 


\section{Abstract}

Background: Previous studies in Ethiopia indicated that tuberculosis (TB) patient's elapse long time before treatment initiation. However, there is very limited evidence on the association of delay to initiate treatment with treatment outcome. Objective: To investigate the association of time to treatment initiation delay with treatment outcomes of new adult TB patients in Tigray region of Ethiopia. Methods : We conducted a follow up study from October 2018 to April 2020 by recruiting 875 newly diagnosed Pulmonary Tuberculosis (PTB) patients from 21 randomly selected health facilities. Study participants were selected using simple random sampling technique during treatment initiation from October 1/2018 to October 30/2019. Delay to initiate treatment and treatment outcome were collected using standardized questionnaire and laboratory investigation. Adherence of TB patients to their treatment was collected using a 10 points linear visual analogue scale (VAS) at the end of treatment. The association of delay to initiate treatment with treatment outcome was modeled using log binomial regression model. Statistical significance was reported whenever $p$-value was less than 0.05 . Data was analyzed using SPSS software version 21. Result: The median total delay to treatment initiation was 62 days with inter-quartile range of 16-221 days. A unite increase in a day to initiate treatment results in increment of risk of unsuccessful treatment outcome by 2.3. Other factors associated with unsuccessful treatment outcomes were being less adherent to the treatment, HIV co infection, being smear positive at initiation of treatment and after 2 months of treatment initiation. Conclusion : delay in a day to initiate treatment is associated with increased risk of unsuccessful treatment outcome. Any effort targeted towards reducing the negative effects of PTB should target on strategies that reduces the length of delay to initiate treatment and strengthen community engagement to improve treatment adherence of patients that have started treatment.

\section{Introduction}

In 2018, an estimated 10 million people developed TB disease and $8.6 \%$ of these individuals were HIV positive. In the same year there were about half a million new cases of rifampicin-resistant TB and $78 \%$ of them were multidrug-resistant TB (1). In 2019 there were 161,000 new TB cases, 27,000 deaths and 1,600 drug resistant TB cases making Ethiopia one of the 30 high-TB -burden countries (2).

To halt the burden attributable to TB, WHO developed the End TB Strategy which includes ending the TB epidemic by eliminating catastrophic expenses due to TB, reducing deaths by $95 \%$ and by attaining $90 \%$ reduction in the incidence TB by $2035(1,3)$. Early detection of TB cases and initiating treatment for the detected cases are main pillars for the End TB strategy (4). Nonetheless, patients elapse very long time to initiate care for their illness and to start treatment in different parts of the world (5-7) and in Ethiopia (810). For example median number of days to initiate treatment is 60 days in Tigray $(11,12), 97$ days in Bale (13) and 64 days in Addis Ababa (10). Delayed treatment intuition results in more serious clinical illness, increased length of infectiousness and poor treatment outcomes including mortality and drug resistance $(14,15)$. The increased length of infectiousness also increases disease transmission within the community and creates a favorable condition for TB epidemic $(9,15)$. In contrast to these findings, in 
Israel successful treatment outcome was not associated with patient delay and health system delay to initiate treatment (16).

Achieving high treatment success enables to reduce TB related mortality, prevalence of drug resistant TB and transmission of TB in the community (2). In the year 2017 successfully treated TB cases globally was $85 \%$ and it was $89 \%$ in Ethiopia $(2,17)$. However, compared to the treatment success, cure rates of TB patients is still low at $81 \%$ in Ethiopia which ranges from $38-92 \%$ in different parts of the country (18)

In previous studies patient related, socio-demographics, lifestyle and behavioral, clinical, and bacteriologic profile were significantly associated with unsuccessful TB treatment outcomes $(19,20)$. Despite of the long time elapsed to initiate TB treatment and poor treatment outcomes in different parts of Ethiopia, there is very limited evidence that investigated the effect of delay to initiate treatment on the outcome of TB treatment provided to the TB patients. This study investigated association of delayed treatment initiation with treatment outcomes of TB patients. Findings from this study will be an evidence for program people in designing interventions that reduce new TB infection and improve treatment success.

\section{Methods And Materials}

\section{Study setting}

Tigray is one of the nine Regional States of Ethiopia with an estimated 5.3 million population (21). There are 712 health posts, 214 health centers and 38 hospitals ( 1 specialized hospital, 15 general hospitals, 22 primary hospitals) in the region. The study was conducted in 21 health facilities (five hospitals and 16 health centers) in two zones of Tigray, Northern Ethiopia. The two study Zones (Eastern and Mekelle) harbor an estimated 2 million people (21). During the data collection period almost all health facilities were providing directly observed short-course tuberculosis treatment by trained health workers (TB focal persons). The program was introduced in all hospitals, health centers and in most of the health posts (21).

Diagnosis and treatment of all forms of TB across Ethiopia has been based on the national TB control guidelines that specify case definitions, diagnostic and treatment standards (18). Thus all TB cases enrolled for this study were diagnosed using Genexpert, sputum smear microcopy or clinical signs aided with $\mathrm{x}$-ray (18). The treatment regimens for all new adult cases of TB were treated with combination of Ethambutol(E), Rifampicin(R), Isoniazid(H) and pyrazinamide(Z) for the first two months (2ERHZ) followed by Rifampicin $(\mathrm{R})$ and Isoniazid $(\mathrm{H})$ combinations for the remaining six months $(4 \mathrm{RH})(18)$.

\section{Study design, aim and period}

A follow-up study with the aim of investigating the effect delayed treatment initiation of PTB on treatment outcome was conducted from October 2018 to April 2020 in 21 health facilities (five hospitals and 16 health centers) in Eastern and Mekelle zones of Tigray Regional State of Ethiopia that harbor an estimated 2 million people. 


\section{Reference population}

All newly diagnosed PTB patients and initiated treatment in all health facilities in Tigray Regional State of Ethiopia.

\section{Study population}

All newly diagnosed PTB cases who initiated treatment from October 2018 to April 2020 in the 21 health facilities selected for the current study.

\section{Inclusion criteria}

All newly diagnosed PTB patients whose age is 18 years or more, with no previous treatment history of TB, were eligible for the study. All Patients who were diagnosed and initiated treatment within the study settings but moved to another place inside the study area were eligible. However; patients diagnosed and started treatment out of the study area but transferred in to the study area were not eligible.

\section{Sample size and sampling technique}

The sample size was computed using StatCalc program of Epi-Info at $95 \%$ significance level, $80 \%$ power, considering design effect of 1.5. This is assuming that a unit change in time to initiate PTB treatment results in increment of risk of unsuccessful treatment outcome by 2.02 (risk ratio) and $5.8 \%$ of the patients with unsuccessful treatment outcome (22), the required sample size at the end of the follow-up was 489 . However, the sample size for assessing predictors of delay computed using $95 \%$ significance level, $80 \%$ power, expected frequency of exposure (visit to non-DOTS center) among controls of $43 \%$ and odds ratio (OR) 1.63 (11) with design effect of 1.5 and $4 \%$ non-response rate; provided a total of 875 new cases. Hence, the same cases were followed for the outcome; the larger sample of 875 was taken the final sample size.

The total sample size was proportionally allocated to each health facility based on the average number of TB cases reported by the facility in the previous 2 years. List of eligible patients extracted from daily list of TB patient clinic in each facility was used as our sampling frame to select study participants allocated to that facility $(8,15)$. Each TB patient's registration numbers of TB patients written on the TB registration book in clinical management was used in the random sampling process and the patients were recruited prospectively during treatment initiation. The number of patients selected from each health facility was obtained by dividing the number of study participants allocated to each of health facility to the total number of data collection time (one year).

\section{Data collection}

A structured questionnaire was used to collect the data which was adapted from tools used elsewhere (22-24) and standard TB register book (25). Besides, eligible cases were interviewed for sociodemographic, health care seeking, and lifestyle. The following data were also collected from the study participants:

\section{Exposure and outcome data}


The main exposure variable was delay to initiate treatment (total delay) measured by number of days elapsed between onsets of illness and time to initiation of anti-TB treatment. This delay was computed as a sum of patient and health system delay. The main outcome variable was treatment outcome which was ascertained based on standard definitions $(26,27)$. For the purpose of this paper this outcome was categorized as binary (favorable versus non-favorable outcome)

\section{Treatment adherence data}

was collected using a 10 points linear visual analogue scale (VAS) (ranging from $0 \%=$ no single dose taken; to $100 \%=$ no single dose missed) at the end month of treatment, where patients were asked 'How much of your prescribed TB medications have you taken until now in the course of your treatment?' The VAS method was chosen because I) it can be used to assess TB treatment adherence for the whole duration of anti-tuberculosis treatment rather than at a specific time. II) VAS was used to assess adherence to anti-tuberculosis treatment in another study conducted in the same study area, and was found to be accurate (29). Study participants with adherence level above $90 \%$ were considered as adherent based on the World Health Organization (WHO) adherence definition (30) and national guideline (27).

\section{Clinical data}

symptoms (respiratory symptoms, constitutional symptoms, or both), and the time duration from onset of symptom up to treatment initiation. Respiratory symptoms included dyspnea, hemoptysis, cough, or expectoration while constitutional symptoms included malaise, loss of appetite, weight loss, fatigue, fever, chills, chest pain or night sweats.

\section{Laboratory investigation}

Smear status of all study participants was determined. This was done during treatment initiation, 2nd and 6th month of treatment initiation. One spot sputum specimen (about $5 \mathrm{ml}$ ) was collected. Two direct smears were prepared from the specimens for Ziehl-Nielsen (Z-N) staining. The smear preparation and Ziehl-Nielsen (Z-N) staining were performed according to the standard operating procedure $(25,26)$.

\section{Data quality and management}

A total of 18 nurses with BSc degrees collected the data and 3 Senior BSc degree nurses supervised the field data collection process. These data collectors and supervisors were trained on the objectives of the study, the importance of the findings and on how to collect the data from study participants. The training also included description of questionnaire, interviewing techniques. Pretest was done at nearby health facilities not included in the study. The PI cross checked the interview for $10 \%$ of the study participants. Efforts were made to minimize recall bias by using local calendars listing main religious and national days to define the perceived date of onset of cough (TB symptoms) and time of first health seeking. The questionnaire was translated into regional language (Tigrigna) spoken by almost all residents in the study area. 


\section{Data analysis}

Data was entered, cleaned and analyzed using SPSS software version 21 (29). The data were described using frequency, proportions, measures of location and dispersion (to calculate the mean and median. As total delay was not normally distributed; the data was transformed before analysis. During analysis delay was considered as continuous variable. Association between the exposure and outcome (unsuccessful vs successful) was determined by log binomial regression model. Accordingly, both simple and multiple logbinomial models were fitted to estimate crude and adjusted relative risk (RR) of the outcome variables. The goodness of fit of the model was assessed using Pearson chi-square and Deviance tests. In all the statistical tests, statistical significance was judged at $p<0.05$.

\section{Operational definitions}

\section{Total delay}

is the time from the onset of TB symptoms to the first start of anti-TB treatment.

\section{Treatment outcomes}

were categorized into successful or favorable and unsuccessful or unfavorable treatment outcomes.

\section{Successful treatment outcome}

includes treatment completed with or without the evidence of cure.

\section{Unsuccessful treatment outcome}

includes treatment failure cases, patients who died and defaulted patients.

\section{Cured}

if he/she became smear or culture negative in the last month of treatment and on at least one previous occasion; including, a patient with a positive Xpert MTB/RIF test at baseline can be declared cured if a negative smear result is recorded at the end of treatment.

\section{Treatment completed}

if he/she completed treatment with resolution of symptoms (26).

\section{Treatment failure}

a patient, who becomes smear or culture positive at five months or later during treatment or harbors a multi-drug resistant (MDR) strain at any point of time during the treatment.

\section{Died}

a patient who died for any reason while he/she were on treatment for TB. 


\section{Defaulter}

a defaulter is a patient who has been on treatment for at least four weeks (26).

\section{Results}

Socio-demographic, clinical characteristics and accessibility to health facilities of study participants

A total of 875 newly diagnosed adult pulmonary tuberculosis patients were enrolled from 16 health centers and 5 hospitals. The median age [inter-quartile range (IQR)] of the study participants was 35 (2545) years, $58.1 \%$ were males, and $54.5 \%$ were from urban areas. Regarding to educational status, 390 (47.5\%) were lower than secondary school, 314 (39.9\%) were secondary school and the remaining 93 (12.6\%) college and above. Participants with $28.7 \%$ and $26.6 \%$ had a BMI of below 18 and below 16 , respectively. Similarly, 39.6\% had MUAC below $220 \mathrm{~mm}$ and $23.5 \%$ had MUAC measurement of below $200 \mathrm{~mm}$. Among the study participants $57 \%$ were living within the distance of less than $10 \mathrm{KM}$ from the nearest health facility.

\section{Tuberculosis treatment initiation delay}

The median total delay of the study participants were 62 days with inter-quartile range of 16-221 days. The mean total delay of the study participants were $125 \pm 256(\mathrm{sd})$ days. TB patients with age of more than 45 years old had the highest median delay to initiate TB treatment compared to the other age groups. Similarly, rural residents, house wives and those TB patients who made more than one visit to health facility had higher median time of delay to initiate TB treatment compared to their counter parts. Furthermore; TB patients with MUAC measurement of lower than $200 \mathrm{~mm}$ and who traveled for more than $10 \mathrm{KM}$ had delayed longer to initiate TB treatment (Table 1). 
Table 1

median delay results of the different delay categories among TB cases in two zones of Tigray, Northern Ethiopia, 2020

\begin{tabular}{|c|c|c|c|c|c|c|c|}
\hline \multirow[t]{2}{*}{ Variable } & & \multicolumn{2}{|c|}{ Patient delay } & \multicolumn{2}{|c|}{$\begin{array}{l}\text { Health system } \\
\text { delay }\end{array}$} & \multicolumn{2}{|c|}{ Total delay } \\
\hline & & Median & $\begin{array}{l}\mathrm{p} \\
\text { value }\end{array}$ & Median & $\begin{array}{l}\mathrm{p} \\
\text { value }\end{array}$ & Median & $\begin{array}{l}P \\
\text { value }\end{array}$ \\
\hline \multirow[t]{2}{*}{ Sex } & Male & 30 & 0.854 & 17 & 0.669 & 62 & 0.854 \\
\hline & Female & 30 & & 20 & & 62 & \\
\hline \multirow[t]{3}{*}{ Age } & $18-25$ & 30 & 0.007 & 9 & 0.474 & 46 & 0.007 \\
\hline & $26-44$ & 30 & & 19 & & 62 & \\
\hline & $>45$ & 35 & & 25 & & 73 & \\
\hline \multirow[t]{2}{*}{ HIV result } & Positive & 30 & 0.554 & 19 & 0.81 & 63 & 0.6 \\
\hline & Negative & 30 & & 22 & & 54 & \\
\hline \multirow[t]{2}{*}{ Residence } & Urban & 22 & 0.000 & 11 & 0.000 & 33 & 0.000 \\
\hline & Rural & 72 & & 33 & & 117 & \\
\hline \multirow[t]{3}{*}{ Marital status } & Single & 30 & 0.000 & 8 & 0.004 & 46 & 0.000 \\
\hline & Married & 57 & & 21 & & 67 & \\
\hline & Divorced/Widowed & 30 & & 31 & & 73 & \\
\hline \multirow{9}{*}{$\begin{array}{l}\text { Educational status } \\
\text { Occupation }\end{array}$} & $\begin{array}{l}\text { Lower than } \\
\text { secondary school }\end{array}$ & 30 & 0.053 & 21 & 0.008 & 65 & 0.053 \\
\hline & Secondary & 31 & & 9 & & 68 & \\
\hline & College and above & 30 & & 7 & & 41 & \\
\hline & Farmer & 30 & 0.001 & 22 & 0.01 & 69 & 0.001 \\
\hline & Housewife & 35 & & 23 & & 72 & \\
\hline & Employed & 28 & & 14 & & 64 & \\
\hline & Daily laborer & 30 & & 14 & & 42 & \\
\hline & Student & 23 & & 5 & & 33 & \\
\hline & Unemployed & 30 & & 25 & & 65 & \\
\hline \multirow[t]{2}{*}{ First action taken } & Visited HF & 30 & 0.000 & 16 & 0.000 & 52 & 0.000 \\
\hline & Other actions ${ }^{a}$ & 51 & & 24 & & 118 & \\
\hline
\end{tabular}




\begin{tabular}{|c|c|c|c|c|c|c|c|}
\hline \multirow[t]{2}{*}{ Variable } & & \multicolumn{2}{|c|}{ Patient delay } & \multicolumn{2}{|c|}{$\begin{array}{l}\text { Health system } \\
\text { delay }\end{array}$} & \multicolumn{2}{|c|}{ Total delay } \\
\hline & & Median & $\begin{array}{l}\mathrm{p} \\
\text { value }\end{array}$ & Median & $\begin{array}{l}\mathrm{p} \\
\text { value }\end{array}$ & Median & $\begin{array}{l}P \\
\text { value }\end{array}$ \\
\hline \multirow{2}{*}{$\begin{array}{l}\text { Distance to the } \\
\text { nearest health } \\
\text { facility }\end{array}$} & $\leq 10 \mathrm{~km}$ & 28 & 0.2 & 16 & 0.244 & 58 & 0.115 \\
\hline & $>10 \mathrm{~km}$ & 34 & & 22 & & 67 & \\
\hline \multirow[t]{2}{*}{ Knowledge on TB } & Poor & 30 & 0.892 & 16 & 0.8 & 62 & 0.1 \\
\hline & Good & 29 & & 18 & & 62 & \\
\hline Visited $>1 \mathrm{HCF}$ & Yes & 40 & 0.000 & 32 & 0.000 & 63 & 0.000 \\
\hline \multirow{3}{*}{$\begin{array}{l}\text { Distance to the } \\
\text { nearest health } \\
\text { facility (in KM) }\end{array}$} & No & 23 & 0.000 & 12 & 0.000 & 30 & 0.000 \\
\hline & $\leq 10$ & 23 & & 12 & & 58 & \\
\hline & $>10$ & 40 & & 25 & & 67 & \\
\hline \multirow[t]{3}{*}{ MUAC (in MM) } & $>220$ & 47 & 0.000 & 23 & 0.000 & 52 & 0.000 \\
\hline & $200-220$ & 30 & & 7 & & 64 & \\
\hline & $<200$ & 40 & & 32 & & 74 & \\
\hline
\end{tabular}

\section{Association of treatment initiation delay with TB treatment Outcomes}

Overall, 797(91.1\%) study participants had successful treatment outcome (cured and treatment completed) and 78 (8.9\%) study participants had unfavorable treatment outcome (treatment failure, death and defaulter) (Fig. 1). The overall cure rate and treatment complete was $69.2 \%$ and $21.9 \%$, respectively. On the other hand, $5.5 \%$ of TB patients were died and $2.3 \%$ with treatment failure. TB patients with successful treatment outcome had initiated treatment with a median delay of 54 days with 31 to 71(IQR) whereas TB patients with unsuccessful treatment outcome had initiated TB treatment after a median delay of 256 days with 112 to 264 (IQR).

Regarding treatment adherence, from the total 875 study participants, treatment adherence was measured for $94.4 \%(817 / 875)$ and treatment adherence was not documented for the remaining 58 study participants. Seven hundred seventy three $(94 \%)$ study participants had complete treatment adherence or adherent above $90 \%$, while the remaining $45(6 \%)$ had incomplete treatment adherence or non-adherent.

The result of log binomial regression model showed that a unite increase in a day to initiate treatment results in an increase of risk of unsuccessful treatment outcome by 2.3 (Adjusted relative risk (ARR) $=2.3$, $95 \% \mathrm{Cl} ; 1.32-3.38$ ) (Table 1). Being non-adherent to treatment, (ARR $=2.1,95 \% \mathrm{Cl} ; 1.18-2.94)$, HIV co- 
infection (ARR $=2.5,95 \% \mathrm{Cl}$; 1-5.8), being smear positive at initiation of treatment (ARR $=3.6,95 \% \mathrm{Cl} ; 1.2-$ 10.7), being smear positive after 2 months of treatment initiation (ARR $=5.7,95 \% \mathrm{Cl} ; 2.7-18.5)$ and being secondary school (ARR $=2.1,95 \% \mathrm{Cl} ; 1.14-4.33)$ are significantly associated with higher risk of unsuccessful treatment outcomes.

Table 1

Associations of treatment initiation delay with risk of attaining unsuccessful treatment outcomes among newly diagnosed PTB patients in selected health facilities of Tigray, Northern Ethiopia $(n=875)$

\begin{tabular}{|c|c|c|c|}
\hline \multirow[t]{2}{*}{ Measures of Effect } & \multicolumn{2}{|c|}{ Treatment success } & \multirow[t]{2}{*}{ Risk ratio(95\% Confidence Interval) } \\
\hline & Successful & Unsuccessful & \\
\hline Crude effect & 797 & 78 & $3.4(2.69-4.17)$ \\
\hline $\begin{array}{l}\text { Partially adjusted } \\
\text { effect }\end{array}$ & 797 & 78 & $2.4(1.36-3.43)$ \\
\hline Fully adjusted effect & 797 & 78 & $2.3(1.32-3.38)$ \\
\hline
\end{tabular}


Table 2

Associations of selected characteristics and risk of attaining unsuccessful treatment outcomes among newly diagnosed PTB patients in selected health facilities of Tigray, Northern Ethiopia $(n=875)$

\begin{tabular}{|c|c|c|c|c|c|}
\hline \multirow[t]{2}{*}{ Variables } & \multirow[t]{2}{*}{ Categories } & \multicolumn{2}{|c|}{ Treatment success } & \multirow{2}{*}{$\begin{array}{l}\text { Crude } \\
\text { Relative } \\
\text { Risk (CRR) }\end{array}$} & \multirow{2}{*}{$\begin{array}{l}\text { Adjusted } \\
\text { Relative } \\
\text { Risk (ARR) }\end{array}$} \\
\hline & & Successful & Unsuccessful & & \\
\hline \multirow{2}{*}{$\begin{array}{l}\text { Treatment } \\
\text { adherence score }\end{array}$} & Non-adherent & 37 & 8 & $\begin{array}{l}2.1(1.18- \\
2.94)\end{array}$ & $\begin{array}{l}2.4(1.26- \\
3.51)^{\star}\end{array}$ \\
\hline & Adherent & 760 & 21 & 1.00 & 1.00 \\
\hline \multirow[t]{4}{*}{ Age } & $18-25$ & 211 & 17 & \multirow{2}{*}{$\begin{array}{l}0.63(0.34- \\
1.2)\end{array}$} & $1(0.37-2.8)$ \\
\hline & $26-44$ & 360 & 32 & & \multirow{2}{*}{$\begin{array}{l}0.5(0.21- \\
1.2)\end{array}$} \\
\hline & \multirow[t]{2}{*}{$\geq 45$} & \multirow[t]{2}{*}{226} & \multirow[t]{2}{*}{29} & $\begin{array}{l}0.69(0.41- \\
1.2)\end{array}$ & \\
\hline & & & & 1.00 & \\
\hline \multirow[t]{4}{*}{ Education } & \multirow{2}{*}{$\begin{array}{l}\text { Lower than } \\
\text { secondary school }\end{array}$} & 390 & 27 & $\begin{array}{l}2.1(0.85- \\
7.1)\end{array}$ & $4.1(0.45-36)$ \\
\hline & & 314 & 35 & \multirow{2}{*}{$\begin{array}{l}3.8(1.2- \\
11.7)\end{array}$} & \multirow{2}{*}{$\begin{array}{l}2.1(1.14- \\
4.33)^{\star}\end{array}$} \\
\hline & \multirow{2}{*}{ College and above } & 93 & 16 & & \\
\hline & & & & 1.00 & 1.00 \\
\hline \multirow[t]{3}{*}{ Residence } & Rural & 338 & 61 & \multirow{2}{*}{$\begin{array}{l}4.9(2.8- \\
8.5)\end{array}$} & \multirow{2}{*}{$\begin{array}{l}1.9(0.81- \\
4.5)\end{array}$} \\
\hline & Urban & 459 & 17 & & \\
\hline & & & & 1.00 & 1.00 \\
\hline HIV status & Positive & 86 & 13 & $1.7(0.88-$ & $2.5(1-5.8)^{\star}$ \\
\hline & Negative & 711 & 65 & & 1.00 \\
\hline & & & & & \\
\hline Forms of TB & Smear positive & 251 & 69 & $\begin{array}{l}16.7(8.2- \\
339)\end{array}$ & $\begin{array}{l}3.6(1.2- \\
107)^{*}\end{array}$ \\
\hline & Smear negative & 546 & 9 & & \\
\hline & & & & 1.00 & 1.00 \\
\hline $\begin{array}{l}\text { Smear status } \\
\text { after } 2 \text { months }\end{array}$ & Positive & 19 & 15 & $\begin{array}{l}9.8(4.8- \\
19)\end{array}$ & $\begin{array}{l}5.2(2.7- \\
185 . *\end{array}$ \\
\hline & Negative & 778 & 63 & & \\
\hline & & & & 1.00 & 1.00 \\
\hline X-ray cavitations & Present & 327 & 71 & $14.6(6.6-$ & $2.1(0.59-$ \\
\hline & Absent & 470 & 7 & & \\
\hline & & & & 1.00 & 1.00 \\
\hline $\begin{array}{l}\text { Distance to } \\
\text { health facility }\end{array}$ & $\leq 10$ & 459 & 40 & $0.78(0.49-$ & $\begin{array}{l}0.75(0.44- \\
129)\end{array}$ \\
\hline & $>10$ & 338 & 38 & & \\
\hline & & & & 1.00 & 1.00 \\
\hline
\end{tabular}




\section{Discussion}

In this cohort study we have investigated treatment initiation delay and its association with TB treatment outcome of PTB patients. Hence, here listed below are the main discussion points from the follow up study summarized under two subthemes as association of treatment initiation delay with treatment outcome and other factors affecting treatment outcome.

\section{Association of treatment initiation delay with TB treatment outcome}

A unite increase in a day to initiate treatment results in increment of risk of unsuccessful treatment outcome. This finding is in line with studies from Ethiopia (24) and China (30). The reason for increased risk of unsuccessful treatment outcome with increasing the time to initiate TB treatment could be (i), those TB patients might have severe clinical presentation which is a previously reported predictor of unsuccessful treatment outcomes (14). In this study, those who had not delayed initiating treatment and those who have initiated treatment after a delay of 30 to 60 days had $4 \%$ and $17 \%$ lower risk to develop severe clinical presentation compared to those who have initiated treatment after two and more months (15). (ii), studies had indicated that none formal medication sources (traditional medication, prescribed and self-treatment) are associated with delayed treatment initiation which might lead to poor treatment outcome (8). In the current study, the majority $(64.8 \%)$ of the cases had visited at least two times until the actual diagnosis of TB is made at which time both self and prescribed medicines had been used (8).

\section{Other factors associated with TB treatment outcome}

In the current study HIV co-morbidity increase risk of unsuccessful outcome which is similar with other studies in Ethiopia $(24,31,32)$. The increased risk of unsuccessful outcome among the HIV co infected could be due to the complex and overlapping drug interactions, toxicities, and TB-associated immune reconstitution inflammatory syndrome (33). Furthermore, this increased risk might also be associated with lower uptake of TB/HIV collaborative interventions.

Being smear positive at initiation of treatment is associated with higher risk of unsuccessful treatment. This study result is supported by previous reports in Ethiopia (20) and elsewhere (34). This might be due to the reason that patients with smear-positivity have more advanced disease which leads to lower tuberculosis treatment response. This might also be due to the heavy initial bacillary load which is associated with delay in smear conversion leading to treatment failure and death (35).

Similar to other studies in Ethiopia $(36,37)$ and elsewhere $(35)$ being smear positive after 2 months of treatment initiation was associated with poor treatment outcome. This could be related with patient attitude and behavior towards the disease (36). Patients may feel better and assume they are cured by the subsidence of symptoms after completing the initiation phase. On the other hand, patients may also loss interest in continuing treatment if symptoms persist and no improvements are seen after the initial phase of treatment. The other reason might be related with partly emergence drug resistance. 
But this research had limitations like measurement of the exposure relied on patient self-report which is liable to recall bias. However, we tried to minimize this bias through interviewing patients soon after diagnosis and helping them to recall using local events like national holidays, religious days, and dates of some events. Second, we studied only new PTB and adult cases so that the findings cannot be generalized to all forms of TB cases among all age groups. On the other hand, relatively large sample, geographic coverage (include all levels of the health care system), reduced selection bias through random enrolment, able to measure treatment adherence, being prospective design, direct estimation of risk and use of standard outcome ascertainment could be mentioned as strength of the study. Therefore, the study is valid and could be applied to new TB cases in similar settings.

\section{Conclusion And Recommendation}

Patients experience long time to initiate treatment in Tigray, northern Ethiopia. A unite change in a day to initiate TB treatment is associated with increased risk of unsuccessful treatment outcome. Similarly, patients with poor treatment adherence, being HIV positive, being smear positive at initiation of treatment, being smear positive after 2 months of treatment initiation and being or completed secondary school independently predicted higher risk of unsuccessful treatment outcomes. Hence, multiple interventions are needed to halt the long time taken to initiate treatment like health education about TB, making those advanced diagnostic tools more accessible to the local community mainly to the rural areas, introducing universal screening for those who have cough regardless of the time of cough starts. Delayed treatment initiated TB patients should be identified early or during treatment initiation and should be closely monitored throughout the course of treatment. Community engagement in the treatment package of direct observed treatment strategy (DOTS) to improve tuberculosis patients' treatment adherence. Further study is needed on the role of this long delay on emergence of drug resistance and the mechanisms or interventions needed to halt this high rate of unsuccessful treatment outcome.

\section{Abbreviations}

TB. Tuberculosis

PTB ...Pulmonary Tuberculosis

WHO. ..World Health Organization

HIV... human immunodeficiency virus

MUAC. Mid-Upper Arm Circumference

RIF.. Rifampicin

RR. Relative Risk 


\section{Declarations}

\section{Acknowledgments}

We would like to express our gratitude to Aklilu Lemma Institute of Pathobiology, Addis Ababa University, for giving us the opportunity to undertake this study. We would like also to thank Mekelle University for giving us sponsorship to conduct the research. We would also like to thank all health professionals working in the health facilities where this study was conducted, the study participants and Tigray regional health bureau.

\section{Authors' contributions}

KT wrote the proposal, participated in data collection and drafted the manuscript. AM, GB, GM and NB commented the proposal with great revisions, participated in data analysis and revised drafts of the manuscript. All Authors revised and approved the final manuscript.

\section{Funding}

This is not funded externally.

\section{Availability of data and materials}

All data is contained in the manuscript and other raw data will be provided to readers upon the request to the corresponding author.

\section{Ethics approval and consent to participate}

Ethical approval for this study was obtained from the Research and Ethical Committee of Addis Ababa University, Aklillu Lemma Institute of Pathobiology. A formal permission letter was also obtained from the regional health bureau of Tigray to the selected district health office. Each health facility selected for the study was contacted with a permission letter from the district health office. Each case diagnosed as TB according to the national guideline was consented in a written form before the interview. To assure confidentiality interview with TB case was held in a private room and the information collected was recorded anonymously. All patients were treated according to the national guideline and there was no any interference during the treatment.

\section{Consent for publication}

Not applicable.

\section{Competing interests}

There is no financial and non-financial conflict among the authors. 


\section{References}

1. GA U. Transforming our world: the 2030 Agenda for Sustainable Development. Division for Sustainable Development Goals: New York, NY, USA. 2015.

2. WHO. World Health Organization Global tuberculosis repot 2019. Gevena:: World Health Organization, 2019.

3. WHO EB. 134th session. Global strategy and targets for tuberculosis prevention, care and control after 2015. EB134. R4. 2014.

4. Raviglione M, Director G. Global strategy and targets for tuberculosis prevention, care and control after 2015. World Health Organization, Geneva. 2013.

5. Sadique MZ, Adams EJ, Edmunds WJ. Estimating the costs of school closure for mitigating an influenza pandemic. BMC Public Health. 2008;8(1):135.

6. Odusanya OO, Babafemi JO. Patterns of delays amongst pulmonary tuberculosis patients in Lagos, Nigeria. BMC Public Health. 2004;4(1):18.

7. Xu B, Jiang Q, Xiu Y, Diwan V. Diagnostic delays in access to tuberculosis care in counties with or without the National Tuberculosis Control Programme in rural China. The International Journal of Tuberculosis and Lung Disease. 2005;9(7):784-90.

8. Tedla K, Medhin G, Berhe G, Mulugeta A, Berhe N. Factors associated with treatment initiation delay among new adult pulmonary tuberculosis patients in Tigray, Northern Ethiopia. PLoS One. 2020;15(8):e0235411.

9. Yimer S, Bjune G, Alene G. Diagnostic and treatment delay among pulmonary tuberculosis patients in Ethiopia: a cross sectional study. BMC Infectious Diseases. 2005;5(1):112.

10. Demissie M, Lindtjorn B, Berhane Y. Patient and health service delay in the diagnosis of pulmonary tuberculosis in Ethiopia. BMC Public Health. 2002;2(1):23.

11. Mesfin MM, Newell JN, Walley JD, Gessessew A, Madeley RJ. Delayed consultation among pulmonary tuberculosis patients: a cross sectional study of 10 DOTS districts of Ethiopia. BMC Public Health. 2009;9(1):53.

12. Mesfin MM, Tasew TW, Tareke IG, Kifle YT, Karen WH, Richard MJ. Delays and care seeking behavior among tuberculosis patients in Tigray of northern Ethiopia. Ethiopian Journal of Health Development. 2005;19(I):7.

13. Hussen A, Biadgilign S, Tessema F, Mohammed S, Deribe K, Deribew A. Treatment delay among pulmonary tuberculosis patients in pastoralist communities in Bale Zone, Southeast Ethiopia. BMC research notes. 2012;5(1):320.

14. Virenfeldt J, Rudolf F, Camara C, Furtado A, Gomes V, Aaby P, et al. Treatment delay affects clinical severity of tuberculosis: a longitudinal cohort study. BMJ open. 2014;4(6).

15. Tedla K, Medhin G, Berhe G, Mulugeta A, Berhe N. Delay in treatment initiation and its association with clinical severity and infectiousness among new adult pulmonary tuberculosis patients in Tigray, northern Ethiopia. BMC Infectious Diseases. 2020;20(1):1-10. 
16. Mor Z, Kolb H, Lidji M, Migliori G, Leventhal A. Tuberculosis diagnostic delay and therapy outcomes of non-national migrants in Tel Aviv, 1998-2008. Eurosurveillance. 2013;18(12):20433.

17. Federal Ministry of Health AA, Ethiopia. Health Sector Development Programme IV. Annual Performance Report. EFY 2006 (2013/14). 2014.

18. Ababa A. Federal Democratic Republic of Ethiopia. TRANSPORT. 2016;1:1.

19. Getahun B, Ameni G, Biadgilign S, Medhin G. Mortality and associated risk factors in a cohort of tuberculosis patients treated under DOTS programme in Addis Ababa, Ethiopia. BMC Infectious Diseases. 2011;11(1):127.

20. Berhe G, Enquselassie F, Aseffa A. Treatment outcome of smear-positive pulmonary tuberculosis patients in Tigray Region, Northern Ethiopia. BMC Public Health. 2012;12(1):537.

21. TRHB. Tigray regional health bureau 2017 annual report, Mekelle, Tigray. 2017/18.

22. Organization WH. Diagnostic and treatment delay in tuberculosis. 2006.

23. Kebede A, Alebachew Z, Tsegaye F, Lemma E, Abebe A, Agonafir M, et al. The first population-based national tuberculosis prevalence survey in Ethiopia, 2010-2011. The International Journal of Tuberculosis and Lung Disease. 2014;18(6):635-9.

24. Gebreegziabher SB, Bjune GA, Yimer SA. Total delay is associated with unfavorable treatment outcome among pulmonary tuberculosis patients in west Gojjam zone, Northwest Ethiopia: a prospective cohort study. PLoS One. 2016;11(7):e0159579.

25. Organization WH. Guidance for national tuberculosis programmes on the management of tuberculosis in children. World Health Organization, 20149241548746.

26. Health FMo. Ethiopia-National-guideline-for-TB-Leprosy-and-DR_TB. Addis AbabaAug-2018.

27. Organization WH. Global tuberculosis report 2013: World Health Organization; 2013.

28. Morisky DE, Ang A, Krousel-Wood M, Ward HJ. Predictive validity of a medication adherence measure in an outpatient setting. The Journal of Clinical Hypertension. 2008;10(5):348-54.

29. Chauhan PL, Dhadwal D, Mahajan A. Client's satisfaction with the health services under Janani Suraksha Yojana in rural area of Himachal Pradesh. CHRISMED Journal of Health and Research. 2016;3(3):187.

30. Jianzhao $H$, van den Hof $S$, Lin $X$, Yubang Q, Jinglong $H$, van der Werf MJ. Risk factors for non-cure among new sputum smear positive tuberculosis patients treated in tuberculosis dispensaries in Yunnan, China. BMC Health Services Research. 2011;11(1):97.

31. Asres A, Jerene D, Deressa W. Delays to treatment initiation is associated with tuberculosis treatment outcomes among patients on directly observed treatment short course in Southwest Ethiopia: a follow-up study. BMC pulmonary medicine. 2018;18(1):64.

32. Asres A, Jerene D, Deressa W. Tuberculosis treatment outcomes of six and eight month treatment regimens in districts of Southwestern Ethiopia: a comparative cross-sectional study. BMC Infectious Diseases. 2016;16(1):653. 
33. Shankar EM, Vignesh R, Ellegård R, Barathan M, Chong YK, Bador MK, et al. HIV-Mycobacterium tuberculosis co-infection: a 'danger-couple model'of disease pathogenesis. Pathogens and disease. 2014;70(2):110-8.

34. Wallace RM, Kammerer JS, lademarco MF, Althomsons SP, Winston CA, Navin TR. Increasing proportions of advanced pulmonary tuberculosis reported in the United States: are delays in diagnosis on the rise? American journal of respiratory and critical care medicine. 2009;180(10):101622.

35. Djouma FN, Noubom M, Ateudjieu J, Donfack H. Delay in sputum smear conversion and outcomes of smear-positive tuberculosis patients: a retrospective cohort study in Bafoussam, Cameroon. BMC Infectious Diseases. 2015;15(1):139.

36. Muñoz-Sellart M, Cuevas L, Tumato M, Merid Y, Yassin M. Factors associated with poor tuberculosis treatment outcome in the Southern Region of Ethiopia. The International Journal of Tuberculosis and Lung Disease. 2010;14(8):973-9.

37. Gebrezgabiher G, Romha G, Ejeta E, Asebe G, Zemene E, Ameni G. Treatment outcome of tuberculosis patients under directly observed treatment short course and factors affecting outcome in southern Ethiopia: a five-year retrospective study. PLoS One. 2016;11(2):e0150560.

\section{Figures}

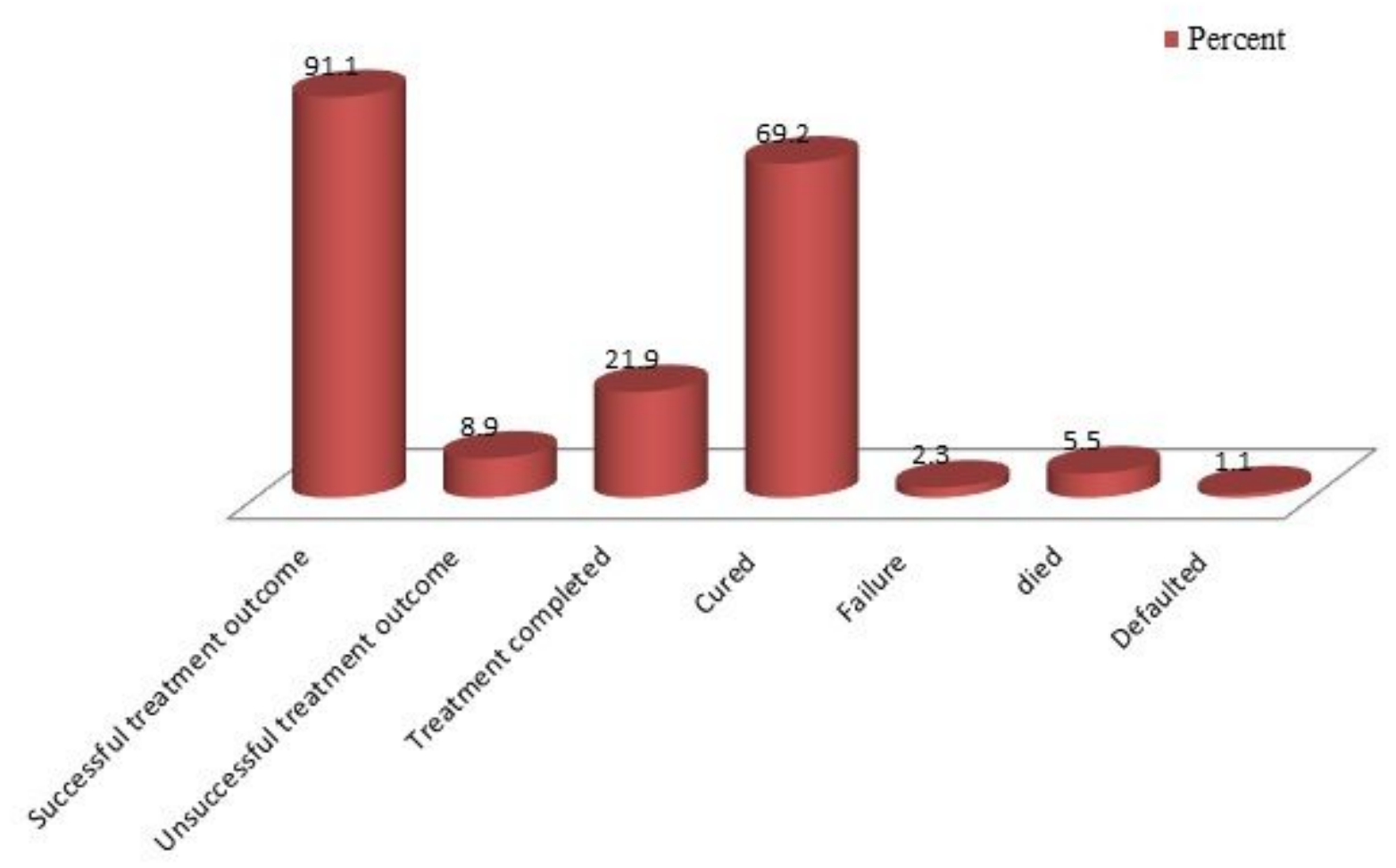

Figure 1 
Treatment outcome of pulmonary tuberculosis patients attending in selected health facilities of two zones of Tigray, Northern Ethiopia, April $2020(n=875)$ 